\title{
Corrigendum
}

\section{Improvements in activities of daily living following functional hand surgery for treatment of lesions to the cervical spinal cord: Self-assessment by patients}

T Meiners, R Abel, K Lindel and U Mesecke

Spinal Cord (2003) 41, 204. doi:10.1038/sj.sc.3101461

Correction to: Spinal Cord (2002) 40, 574-580. doi:10.1038/sj.sc.3101384

Due to an author error, Figures 1 and 2 of the above paper were incorrectly reproduced. The correct versions of both figures are reproduced below:

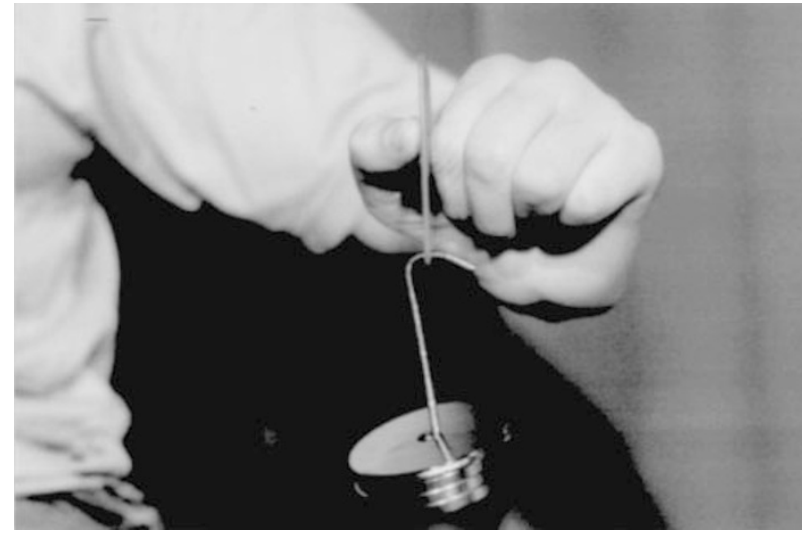

Figure 1 Lateral grasp measurement with plastic plate and weights

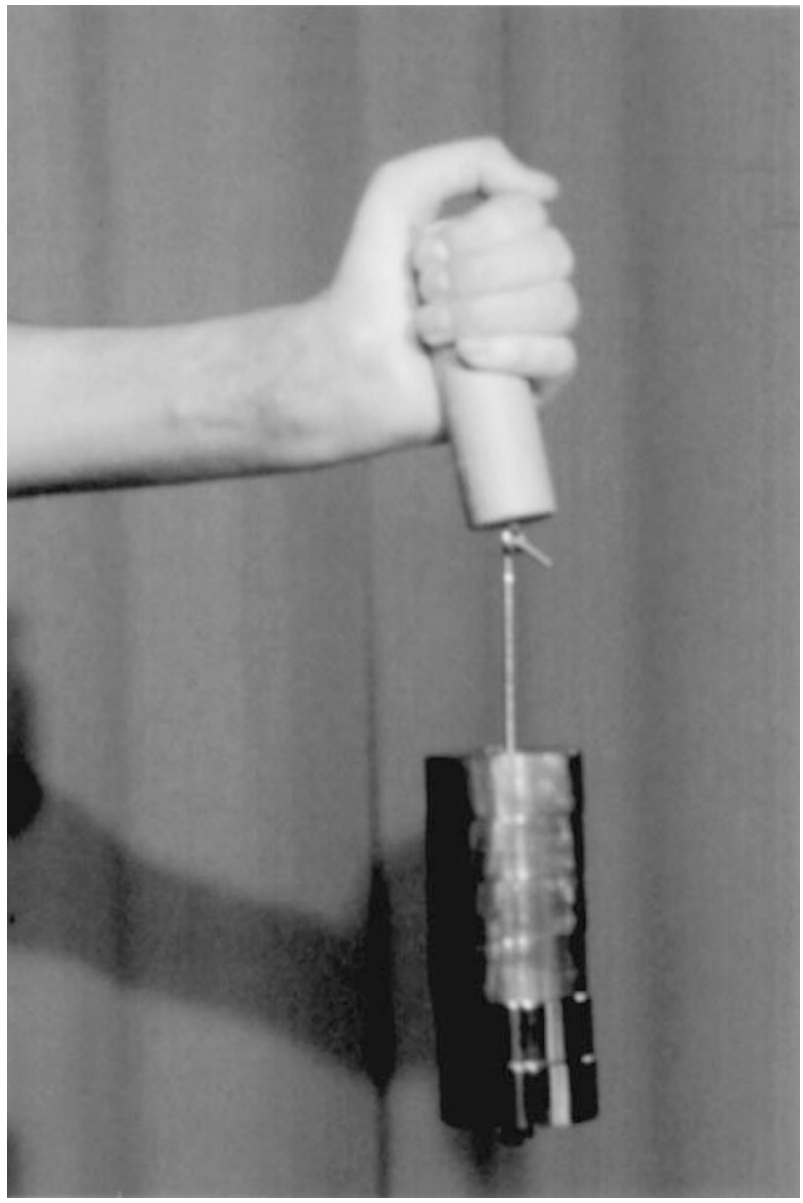

Figure 2 Cylinder grasp measurement with wooden cylinders and weights 